\title{
Sewage and the Farmer
}

\section{A Problem in the Conservation of Waste}

\author{
By W. T. Sedgwick, Sc. D., Professor of Biology and Public Health and Director of the Sanitary Research \\ Laboratories and Sewage Equipment Station, Massachusetts Institute of Technology, Boston
}

[PROF. WILLIAM T. SEDGWICK needs no introduction to those conversant with the story of public
health education and its movements in the United States. Born at West Hartford, Conn., he graduated from the Sheffield Scientific School, Yale University, in 1877, with the degree, Ph.B., gaining Ph.D. at Johns Hopkins in 1881 and receiving Hon.Sc.D. from his alma mater in 1909. He was instructor of physiological chemistry in 1909. He was instructor of physiological chemistry biologist at Johns Hopkins in the latter year, coming to the Massachusetts Institute of Technology in 1883. Here, from assistant professor, he has risen to Professor of Biology and Public Health and Director of the Sanitary Research Laboratory. He is the man who established at the Institute more than twenty-five years ago the courses in biology, later developed into public health work. So successful have they been that the graduates are directing large sanitary works in many parts of the country. Wherever there is an important question of pollution of water supply, or the discussion of conditions inducing infectious disease, he is certain to be consulted. He was one of the experts named by Pittsburgh to investigate the typhoid and Whipple, constitute the non-medical portion of the New York Typhoid Fever Commission.

In an age when popular enthusiasm is seizing on fragments of scientific truth and magnifying them till they overshadow and obscure the fundamental and important facts, he has opposed the present craze for "swatting the fly," which at best is only warring on a symptom and neglecting the disease, or destroying the danger signal, while yet the danger exists. In these later years Prof. Sedguick has stood sturdily for conservation. He is Sedgurck has stood sturdily for conservation. He is
opposed to the wholesale destruction of foods because they are merely of inferior quality, and believes that Government supervision should preserve and make safe such products. This has brought him into disagreement with some of the Government methods. His present article is in the line of conservation of sewage, which is everywhere turned to waste, but which has in it valuable elewhere turned to waste, but which has in it valuable ele-
ments for some of the industrial or agricultural processes. ments for

The farmer is always seeking for fertilizer for his fields and crops. It seems therefore at first sight as if the sewage of our towns and cities ought all to be carefully collected and turned back upon the farms that feed them. The farm feeds the city, why should not the eity, plus air and sunlight, feed the farm? The idea is very old; yet it seems forever new. Chemistry conelement, which, in its virgin state, seems so indifferent so inactive, but in its compounds so full of energy and so much alive - nitrogen flows alike from sea and land, from fisheries and from farms into those living whirlfrom fisheries and from farms into those living whirl-
poods which we call cities, there to revolve for a time and finally to be expelled, largely as sewage, in new chemical combinations, lower and less potent in the scale of energy, but still highly favorable as food stuffs for low plants and animals.

Some such reciprocation between eity and country there actually is. The manure of eity horse stables is carefully saved and sent back to the farm. Garbage is not infrequently likewise saved and sent back to piggeries in the suburbs. The carbonic acid gas given off by human beings, animals, plants and by the great fires and furnaces of cities mingles with the atmosphere and helps to maintain that mighty reservoir of carbonic acid upon which the green plants of sea and land draw for their raw materials for manufacturing starch and for their raw materials for manufacturing starch and
sugar and cellulose- three of the most important elesugar and cellulose-three of the
ments of human life and industry.

\section{How We Waste Nitrogen.}

But water and the nitrogenous wastes of cities are not often thus returned-at least not directly. More often they are emptied as sewage into rivers or harbors or the sea, to mingle there with larger bodies of water which latter material returns to the farmer only after evaparation or distillation into the atmosphere and condensation as rain or snow or hail or fog or dew.

As for the nitrogen of the sewage, this comes back but slowly, if at all, and chiefly in fish, shellfish, seaweod, and other familiar products of the sea, so that there is nowadays a steady and a heavy drain of nitrogen away from the land and into rivers and the sea. The eame thing is true of phosphate, and probably to a underlying plant and animal life. In short, there is to-day a constant sapping of certain indispensable elements of the food of plants and animals from the land to the sea, and only a limited return of these same elements from sea to land. To some extent this drain upon the resources of the land, and that means of the farmer, goes on even in an uninhabited region, for the ground waters which go to feed the streams, and which in dry times make up a very large part of many streams always carry more or less nitrogen.

So, too, there escapes, even from a sewerless eity, and from a region where the excreta of human beings are carefully collected and used in agriculture, through the ground water which comes from such regions, much nitrogen in the form of nitrates.

But undoubtedly the heaviest loss, the greatest But undoubtedly the heaviest loss, the greatest
drain, comes with the sewerage of cities and towns, and the quick discharge of solid streams of sewage directly into rivers or the sea without any previous contact with the earth which, like a mighty sponge would hold the sewage for a time and give opportunity for chemical ehanges followed by absorption and assimilation by plant life. Under this, the modern, system the draining of nitrogen and phosphates away from the land is rapid and continuous; and it is no wonder that great scientists like Sir William Ramsay are giving to the subjects of "nitrogen exhaustion" and "nitrogen supply" anxious consideration.

The Farmers' Interest in the Sewage Question.

But if the sea is just now the gainer and a kind of nitrogen accumulator, ought not the fish to benefit and multiply exceedingly? And, on the other hand, if all sewage should be used in agriculture and our fishing continue or increase, would not the sea soon be depleted of nitrogen and the fisheries disappear? This is an interesting question, but one which we need not try to answer here What we are trying to do is to learn what is the farmer' interest in the sewage question, and that means: How can the farmer best secure the return to his lands of the nitrogen and phosphates which he sends to the city but which the city after using fails to return to him?

The easiest answer is that he should have the liquid wastes of the city at his disposal as he already has the atmospheric wastes and (sometimes) the garbage and the stable manure of eities. In other words, that the sewage streams of eities should be poured, not into rivers or the sea but upon the land, where their precious elements would not be lost or wasted but made over by plants into food for man and beast. This is the simple ideal solutio of the sewage-conservation problem and of the prospective difficulties of the farmer.

\section{The Effect on Fish of Withholding Sewage.}

But it should be noted in passing, that this plan, perfectly carried out, would very likely seriously deplete o at least damage our fisheries, since fish life is rich in nitrogen and the amount of nitrogen in the sea, though immense, is not unlimited. Moreover, the theoretical way out is beset with many practical difficulties. The wors of these is the seasonal and climatic difficulty. Sewage is a constant, daily product of urban life, and must bo disposed of daily and even hourly, rain or shine, in summer and winter, in wet weather as well as dry. But the needs of plant life are not thus constant or perennial, but highly variable, according to season, climate, temperature, rainfall and many other conditions. There is thu this difficulty: If sewage is to be disposed of satisfactorily to the community which has it to get rid of, it must be taken away by river, sea or farmer completely and uninterruptedly; by night and day, summer and winter, rain or shine.

This requirement is easily met by rivers or lakes or the sea, but not by the farmer, at least in regions of marked seasonal variation and considerable rainfall, for at times his crops, simply cannot and will not absorb any additional liquid, however nutritious. Hence th sewage at such times must flow off unpurified and liable to create a nuisance, while the crops suffer from exces of water. In the arid or the semi-arid regions the farme may perhaps at all times and all seasons welcome th arrival of the sewage stream upon his land, for irrigation with sewage ought to be the best and most successful form of irrigation in such regions.

It is certainly a significant fact that very few, if any, successful sewage farms exist to-day in the eastern part of the United States. The subject of sewage disposal ha now been agitated in America for about twenty year improved agriculture have been studied as never before in this country by the U. S. Department of Agriculture and by the Agricultural Colleges and Experiment Stations of the several States; and yet it remains true that there is not one important example of extensive and successful sewage farming in the populous and urban Eastern United States. On the contrary, New York, Boston, Philadelphia, Baltimore, Washington, and many lesser seaboard cities pour their sewage into the sea, while Chicago, Cleveland, Milwaukee, St. Louis, St. Paul, Minneapolis, Cincinnati, Louisville, and many minor cities of the interior empty their sewage into rivers or lakes connected with the sea, so that the farmers nowhere recover from these cities the elements which they contribute to them.

The reason for this common practice is plain. It is easier and cheaper to secure quick, convenient and constant disposal of the huge volumes of sewage which our cities must get rid of, by the means actually adopted than by disposal upon land. And yet, if the sewage of Boston could be carried to Cape Cod, or that of New York to the sands of Long Island, Philadelphia's to the Pine Barrens of New Jersey, or that of Baltimore to the sometimes poor and thirsty soil of the Eastern Shore of Maryland, then might these comparatively desert places be made to blossom like the rose. But even so the fish of the sea would suffer, the gardens of the ocean being robbed to feed those of the land, Perhaps we have here only one phase of a world-old dilemma: the land rising solid from the sea only to be dissolved in rain and carried back to it in aqueous solution; the elements then picked out from the solution by plant and animal life, thoroughly deposited in shells or skeletons, and at death added together to make once more the solid earth

It may be that if we do not use our sewage upon the land we shall by and by be driven to seek our food more and more within the sea. The Japanese and the Chinese eat not only fish but seaweeds, and it would be strange indeed if Americans likewise should give up the land indeed if Americans likewise should give up the land
vegetables of to-day for the sea weeds of to-morrow.

Objections to the Farm Use of Sewage.

From the sanitary point of view the utilization of sewage in farming is open to some serious objections. In the first place, the mere fact that sewage is brought to the farm at all, means that disease germs and parasites may come with it to places and persons previously free from access to a contact with these undesirables. In the second place, owing to the difficulty of escaping contact with it, farm hands, and through them their families, will be especially exposed to personal infection and in some cases to air pollution also. In the third place, certain products of the farm, and especially vegetables such as celery, radishes, turnips, beets and beet tops, spinach, water cress, lettuce, potatoes and onions; and certain berries or other things grown upon or near the earth, such as strawberries and peanuts, which are either eaten unwashed or "handled" preparatory to cooking; if they are irrigated with sewage or are grown on soils recently flooded with sewage, may become soiled with particles of excrement and infected with dangerous microbes or other parasites.

It must be confessed, however, that the experience of Berlin, the capital of the German empire, where the sewage of upward of two millions of people is disposed of upon sewage farms, seems to show that this danger is more theoretical than actual; for the death rate of Berlin from typhoid fever is one of the lowest among the great cities of the world, and the experience of Berlin in this respect is confirmed by that of many smaller cities in England and elsewhere. If it be asked why it is that Berlin, almost alone of all the greater cities of the world, has adopted sewage farming as its means of sewage disposal, the answer is that owing to its inland situation Berlin was compelled to devise some other means than sea disposal, and having only a small stream in its vicinity, was obliged to resort to some form of disposal upon land, i. e., either to intermittent filtration or to broad irrigation (sewage farming). The former is land disposal without reference to the giving of crops, the latter land disposal combined with agriculture or horticulture.

The conclusion of the whole matter is that, except in the more arid portions of the United States, the utiliza tion of sewage in farming does not seem likely to increase at present. Consequently, we may have to look in the future for our supplies of food more to the sea and less to the land. 